\title{
On the mechanical behavior of granite material with particular emphasis on the influence from pre-existing cracks and defects
}

\author{
M. Saadati ${ }^{a, b}$, P. Forquin ${ }^{c}$, K. Weddfelt ${ }^{b}$, P.L. Larsson ${ }^{a}{ }^{,}$, F. Hild $^{d}$ \\ ${ }^{a}$ Department of Solid Mechanics, KTH Royal Institute of Technology, Stockholm, Sweden \\ ${ }^{b}$ Atlas Copco, Örebro, Sweden \\ ${ }^{c}$ 3SR Lab., Grenoble-Alpes University, Grenoble, France \\ ${ }^{d}$ LMT Cachan, ENS Cachan, CNRS, University of Paris-Saclay, Cachan Cedex, France
}

\begin{abstract}
Emailadresses
Mahdi Saadati : $\underline{\text { msaadati@kth.se }}$

Pascal Forquin : pascal.forquin@3sr-grenoble.fr

Kenneth Weddfelt : kenneth.weddfelt@se.atlascopco.com
\end{abstract}

Per-Lennart Larsson : pelle@ hallf.kth.se

Francois Hild : hild@1mt.ens-cachan.fr

\begin{abstract}
In this investigation, experiments are carried out in order to determine the mechanical properties of Bohus granite considering the influence from pre-existing cracks and defects. The experimental investigation aims at a complete material characterization, for the purpose of mechanical analyses using advanced constitutive models, based on a variety of tests. In doing so: Direct tensile and compression tests are performed to evaluate the stiffness and strength; Quasi-oedometric tests are carried out in order to obtain the deviatoric and volumetric behavior of the material at different levels of hydrostatic pressure (up to 860 $\mathrm{MPa}$ ); Three-point bend tests are performed to evaluate the quasi-static strength of the rock and its distribution. Weibull statistics is then employed to describe the strength distribution. The intact specimens indicate a rather low scatter in the mechanical properties such as Young's modulus and tensile strength. However, specimens with large initial defects behave differently. The failure mechanism in these specimens is not as brittle as the intact ones. The crack is opened on the tensile surface of such specimens during the three-point bend test at an early stage during loading, as demonstrated by digital image correlation results.
\end{abstract}

Keywords: Granite, constitutive characterization, pre-existing cracks, quasi-oedometric, three-point bending, digital image correlation (DIC)

*Corresponding author

Email address: pelle@hallf.kth.se 


\section{Introduction}

In order to improve the understanding of failure modes in rock during drilling, a better knowledge of rock mechanical characteristics is required. The percussive drilling method is commonly used in the tunneling and mining industry. The impact of a piston on the drill rod creates a stress wave that is transferred onto the rock through the tool buttons. The rock is then fragmented and flushed out by using water or air. Unlike the situation at quasi-static indentation, the stress waves and rapid indentation make percussive drilling a transient dynamic problem with high local strain rates in the rock [1]. The final aim of this investigation is to numerically simulate the rock fragmentation mechanism during percussive drilling as a dynamic problem. To reach this goal, a constitutive model is needed to deal with both the tensile behavior of the material at high strain rate, because of the fast indentation, and also confined compression behavior that occurs underneath the indenter.

A typical fracture system in rocks during quasi-static indentation is shown in Fig. 1. Different types of cracks are visible in this picture. Also in the region ahead of the indenter, a crushed zone forms due to high compressive stresses. Consequently, there is a need for a need for a good understanding of the mechanical response of rocks when loaded in unconfined tensile stresses, and in confined compression. Except for the crack propagation velocity that is needed to describe the generation of fragments under dynamic loading conditions, all the other material parameters needed to simulation the dynamic fragmentation of rocks can be deduced from the set of tests reported hereafter [2].

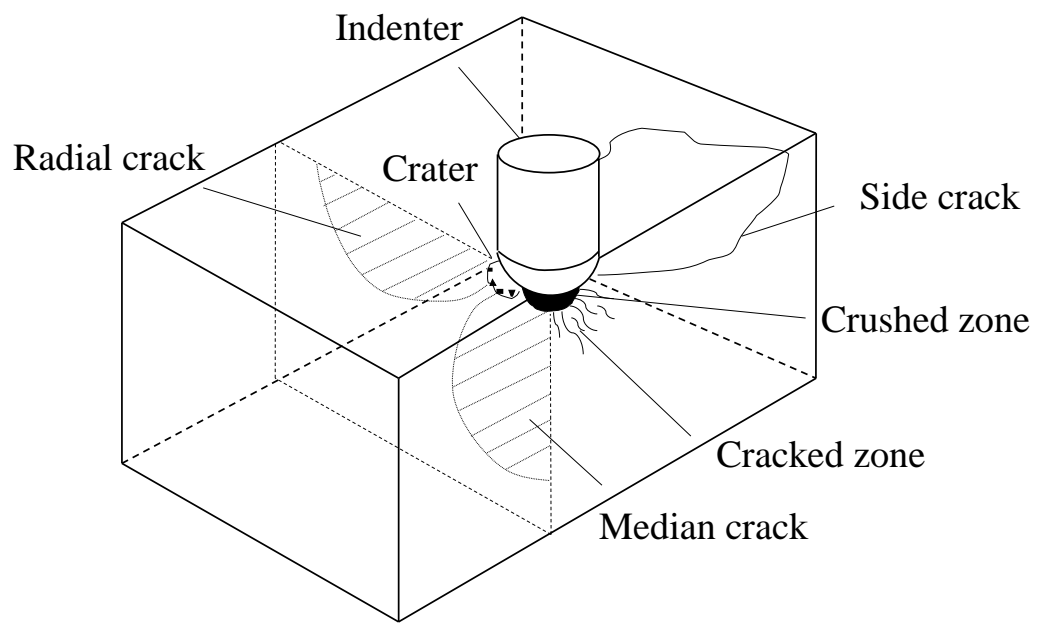

Fig. 1 Fracture system in rock indentation [3].

Moreover, the influence from pre-existing cracks and defects is examined in detail. Basic defects in rocks are voids, pores and microcracks as well as other related features [4]. Such microstructures produce heterogeneity in the strength and stiffness of the material. It is well-known that rock fractures via initiation, growth and coalescence of microcracks, together with sliding between individual grains and the surfaces of microcracks. Associated with these microscopic mechanisms, rock specimens exhibit nonlinear stress-strain responses [4], [5]. Granite, which is the particular material studied in this work, has many pre-existing cracks (see e.g. [6] and [7]), but the porosity is very low (about 0.2\%).Most rocks show a transition from brittle to ductile behavior by increasing the confining pressure. However, silicate rocks 
with low porosity are brittle at room temperature over the whole range of normal laboratory confining pressure up to 0.5-1.0 GPa [8]. Some workers have reported that granite experience brittle fracture even at confining pressures up to 3-4 GPa [9].

Many studies have been performed during the past years to numerically simulate the rock drilling and fragmentation process in brittle materials. Liu [10] developed a rock and tool interaction code $\left(\mathrm{R}-\mathrm{T}^{2 \mathrm{D}}\right)$ and studied the fragmentation process in a quasi-static situation. He used a double elliptic cap strength criterion together with scalar damage for studying rock failure under the action of mechanical tools. Wang et al. [11] used an in-house numerical tool to simulate the rock fragmentation process induced by indentation. The heterogeneity of the rock material is considered and isotropic damage is employed to model progressive degradation of the material. The stress-strain curve is assumed elastic up to a damage threshold, followed by strain-softening. Both Liu [10] and Wang et al. [11] restrict their analyses to 2D plain strain conditions and do not account for inelastic strain. Furthermore, Saksala [12] studied the impact indentation of rocks using an isotropic damage concept for tensile and a viscoplasticity consistency model for compression loading. A parabolic cap was used to describe failure in the high compression region beneath the indenter. This work is performed under 2D plane strain conditions. More recently, the model was improved to deal with 3D simulations [13].

Forquin and Hild [2] studied dynamic fragmentation in brittle materials in general due to impact loading by using a statistical approach for material parameters. The constitutive equation consists of the plasticity model summarized by Krieg [14], Swenson and Taylor [15] for compression that is coupled with the anisotropic damage model developed by Denoual and Hild [16], Forquin and Hild [2] in tension (here and in the sequel referred to as the KST-DFH model). It is shown how a brittle and random behavior under quasi-static loading becomes deterministic and stress-rate dependent when increasing the loading rate. This type of model was able to describe the fragmentation of two grades of limestone [17], dry and wet concrete [18] and microconcrete [19] under spalling tests and edge-on impact experiments.

As already mentioned above, the rock material of interest in the present investigation is granite, and in particular Bohus granite. From an industrial point of view this is a very important material often being encountered in a real drilling situation and, furthermore, also often used at controlled laboratory experiments during development work in order to improve for example drilling efficiency. It is the intention here to perform a complete material characterization of Bohus granite for the purpose of analyzing the mechanical behavior of this material. Often the resulting mechanical problems become complicated and numerical methods (in particular the finite element method) have to be adhered to. This, however, allows for the use of advanced constitutive descriptions of the rock material enabling high accuracy results. The above discussed KST-DFH model is certainly such an advanced description that has shown excellent results when analyzing other types of brittle materials [17, 18, 19]. Accordingly, the present experimental investigation aims at material characterization of Bohus granite but it is also the intention that this characterization should be pertinent to very advanced constitutive models including the issue of dynamic fragmentation. The KST-DFH model naturally then comes to mind but due to the general experimental approach taken, it should be possible based on the results to also determine the material parameters in other constitutive models for rock materials with the intention to perform finite element analyses of the mechanical behavior of granite, both in a dynamic and in a quasi-static situation. The different experiments performed for this purpose, and it's relation to different physical features, are explained immediately below. 
To address the different states of stresses discussed above different experimental tests have been performed. Firstly, direct tensile and compression tests are performed to investigate the mechanical properties of the material such as stiffness and strength. Secondly, quasi-oedometric tests are carried out in order to obtain the deviatoric and volumetric behavior of the material under high confined pressure. The main idea of this test is to axially compress a cylindrical specimen tightly enclosed in a confinement cell. Both axial and radial stresses increase during the loading process and the deviatoric and volumetric response of the material at different level of hydrostatic pressure are obtained from a single test. This type of response can be used in the plasticity model proposed by Krieg [14], Swenson and Taylor [15] to describe the nonlinear response of rocks in confined compression. Thirdly, three point bend tests are performed to evaluate the quasi-static strength of the rock and its distribution. Weibull statistics is then used to describe the strength distribution. The parameters identified herein can be directly used when resorting to a probabilistic approach describing the dynamic fragmentation of brittle materials [2], [16].

In order to summarize then, the structure of the paper is as follows. In section 2, 3 and 4 the different mechanical tests are described and the results are presented. These results are pertinent to material properties to be used at constitutive modelling but also other mechanical features are presented. In section 5 , the particular issue of the presence of pre-existing cracks is scrutinized. Finally, in section 6 , the outcome of the investigation is summarized and discussed, especially so in relation to constitutive modelling of granite.

\section{Direct compression and tensile tests}

Direct compression and tensile tests are performed on granite rock in order to investigate its mechanical properties. In the tensile test, the experimental device is composed of two socket joints to provide a uniform stress field. In the compression case, the specimen is loaded by means of two platens (see Fig. 2). Zwick 1476 load frame is used for both direct compression and tensile tests. Strain gauges and LVDT sensors were used to compare the nominal and local strains. The specimens were in all cases cylindrical $45.7 \mathrm{~mm}$ in diameter and $140 \mathrm{~mm}$ in length and they are obtained using diamond core drill machine.
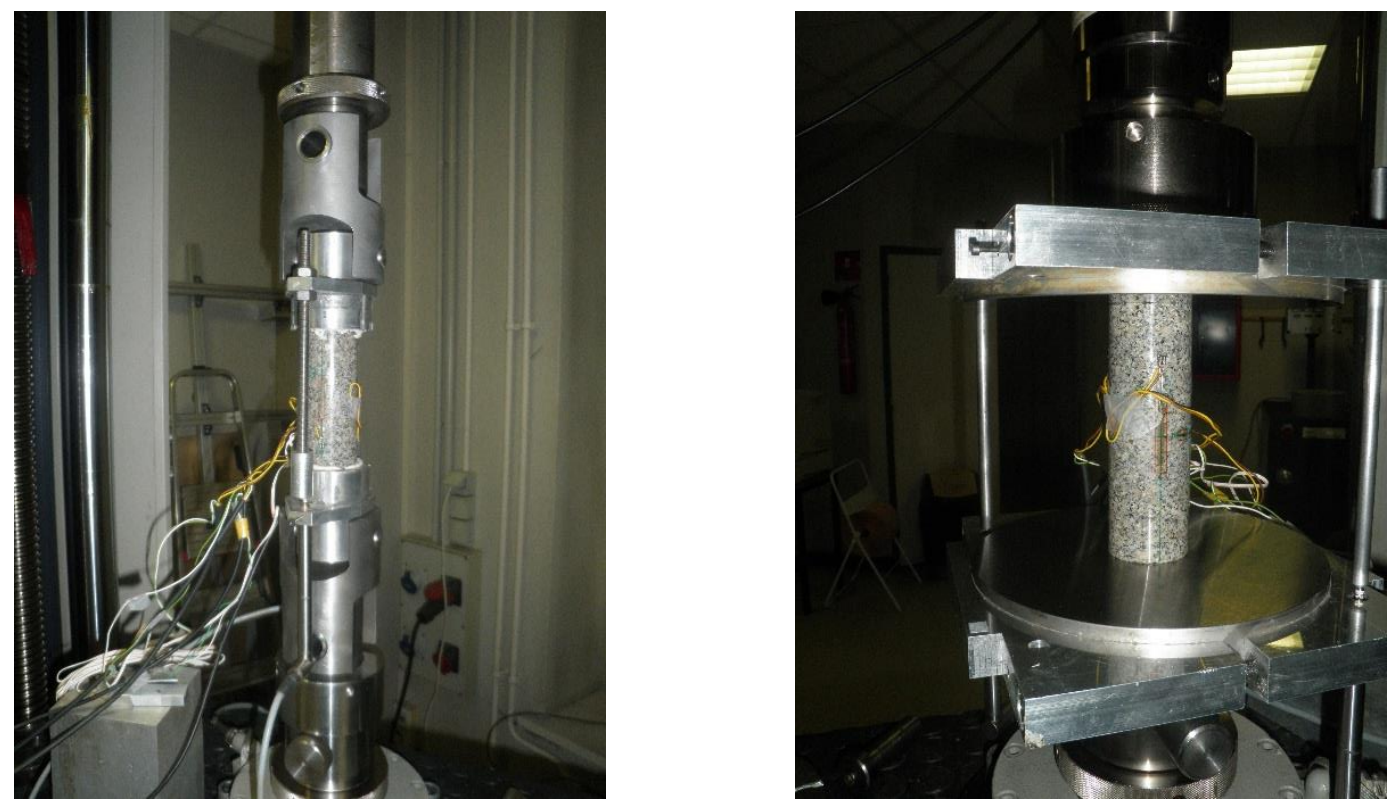
Fig. 2 Experimental setup for direct tensile test (a), and direct compression test (b)

Four direct compression tests are performed at low strain rate $\left(10^{-5} \mathrm{~s}^{-1}\right)$ and more than 2000 samples were recorded for each test. The specimens are first loaded below $30 \%$ of the final failure point (see Table 1). The same specimens are then subsequently loaded in quasi-static tension up to final failure. The results from the compression tests suggest that the specimens can be sorted into two different groups depending on their initial stiffness, from now on referred to as weak and strong specimens.

Table 1 Mechanical properties of granite from quasi-static direct compression test.

\begin{tabular}{|l|l|l|l|l|}
\hline Specimen & $\begin{array}{l}\text { Initial } \\
\text { Elastic } \\
\text { Modulus } \\
(\mathrm{GPa})\end{array}$ & $\begin{array}{l}\text { Max. Strain } \\
(\%)\end{array}$ & $\begin{array}{l}\text { Max. Stress } \\
(\text { No final failure }) \\
(\mathrm{MPa})\end{array}$ & Instrumentation \\
\hline S4 & 32.2 & 0.117 & 54 & Gauge+LVDT \\
\hline S7 & 31.6 & 0.115 & 54 & Gauge+LVDT \\
\hline S99 & 46.7 & 0.155 & 53 & LVDT \\
\hline S100 & 51.2 & 0.093 & 54 & Gauge+LVDT \\
\hline
\end{tabular}

It should be mentioned that the results from LVDT readings include the compression steel platen deformation and therefore only the data from the strain gauges will be used for this test. Results corresponding to one of the weak and one of the strong specimens are shown in Fig. 3. As can be seen, there is a non-linearity in the axial stress-strain behavior at the beginning of the loading stage, in particular in the weak specimen. This is mostly due to the fact that the pre-existing open cracks start to close gradually during loading. Then the behavior becomes linear up to a certain stress limit. The initial elastic modulus of the weak specimen is about $31 \mathrm{GPa}$ increasing up to approximately $52 \mathrm{GPa}$ at higher compressive load levels. In the strong specimen the corresponding initial value is approximately $52 \mathrm{GPa}$ and increasing only slightly at higher loads.

It is of course of interest to compare the results with previous findings for granite in the literature. It was stated in [6] that the increase of the tangent Young's modulus during the initial part of loading following by a constant value is connected to closure of pre-existing cracks in (Chelmsford) granite. The value of the initial elastic modulus is reported in [6], for one crack orientation in Chelmsford granite, to change from slightly more than $30 \mathrm{GPa}$ to a constant value around $55 \mathrm{GPa}$ after a certain load level pertinent to an average $60 \mathrm{MPa}$ of axial stress. These results are in good agreement with the present ones reported above. In this context it should also be mentioned that Saksala [1] reports a somewhat higher value, $80 \mathrm{GPa}$, on the compressive Youngs's modulus for Bukit Timah granite. This value is of course higher than the ones determined here but is obviously for another type of granite material. 


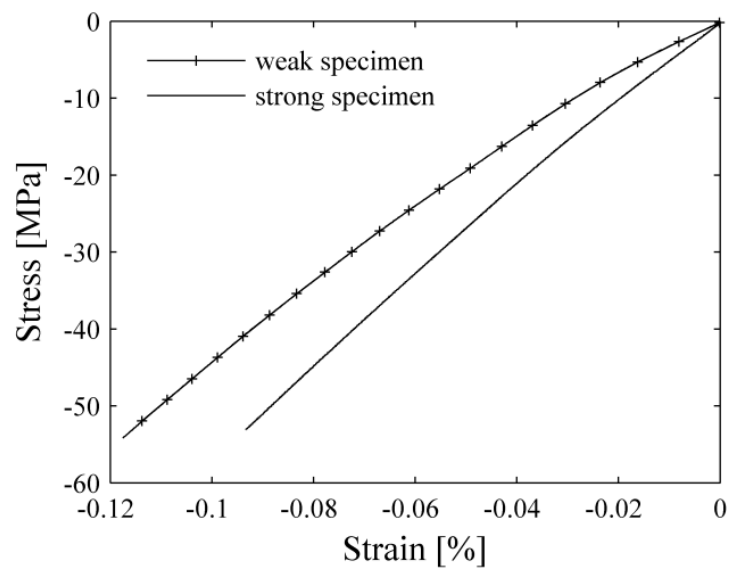

Fig. 3 Axial stress-strain behavior of granite in compression test (test stopped before failure).

Seven direct tensile tests are conducted at low strain rates $\left(10^{-5}\right)$ up to final failure and more than 500 samples were recorded for each test. The quasi-static tensile test results are summarized in Table 2. The reason that some of the specimens are so weak is due to the presence of large pre-existing defects. These large cracks were also seen on the surface of a few other specimens that were not selected for the experiments. The results from the gauges and LVDTs are very similar in these tests.

Table 2 Mechanical properties of granite from quasi static direct tension test.

\begin{tabular}{|l|l|l|l|l|}
\hline Specimen & $\begin{array}{l}\text { Ultimate Strength } \\
(\mathrm{MPa})\end{array}$ & $\begin{array}{l}\text { Ultimate } \\
\text { strain }(\%)\end{array}$ & $\begin{array}{l}\text { Initial } \\
\text { Elastic } \\
\text { Modulus } \\
(\mathrm{GPa})\end{array}$ & Instrumentation \\
\hline S1 & 3.7 & 0.024 & 29 & LVDT \\
\hline S2 & 3.6 & 0.027 & 23 & LVDT \\
\hline S20 & 3.6 & 0.039 & 20 & Gauge+LVDT \\
\hline S4 & 4.9 & 0.032 & 30 & Gauge+LVDT \\
\hline S7 & 5 & 0.034 & 30 & Gauge+LVDT \\
\hline S99 & 8.1 & 0.030 & 46 & LVDT \\
\hline S100 & 8.5 & 0.028 & 50 & Gauge+LVDT \\
\hline
\end{tabular}

The stress-strain behavior of one of the weak (S7) and one of the strong (S100) quasi-static tensile tests is depicted in Fig. 4. As can be seen, there is a noticeable non-linearity in the curve of the weak specimen. The initial elastic modulus is about $30 \mathrm{GPa}$ and it degrades by increasing the load. The opening and coalescence of new cracks during the tensile loading explains this behavior. On the other hand, the strong specimen shows less non-linearity in the stress-strain curve with much higher tensile strength. It should be mentioned that the initial elastic modulus is very similar in compression and tension for both tests. 


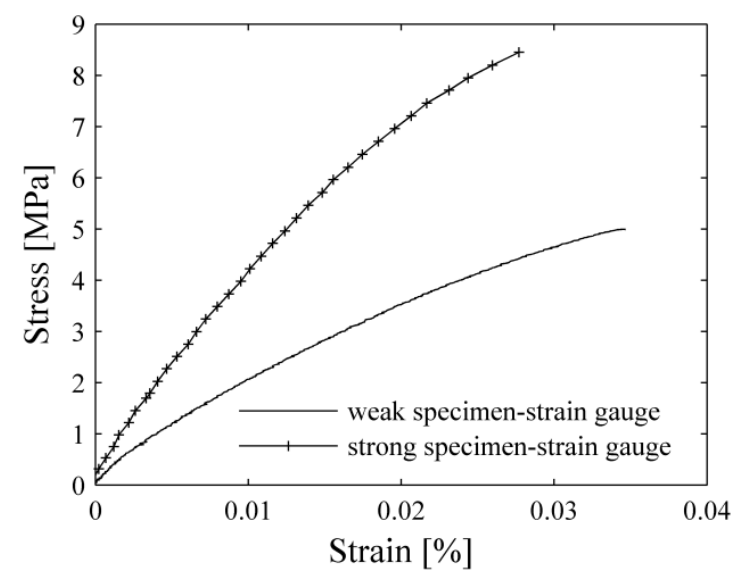

Fig. 4 Axial stress-strain behavior of granite in tensile test.

Two tensile tests with cyclic loading-unloading are performed to investigate the unloading stiffness. The unloading starts at a level of $3 \mathrm{kN}$ and $4.5 \mathrm{kN}$ followed by increasing the load to final failure. The result shows that the unloading stiffness decreases during the test on the weak specimen (S20), which is due to the new open cracks that lead to the material damage. There is also noticeable inelastic strain after each unloading stage which indicates that some of the new open cracks will not completely close after the unloading and therefore cause irreversible strain (Fig. 5). In the case of strong specimens (S100), the stiffness reduction and inelastic strain is almost negligible which means that the specimen is mainly loaded in the elastic regime.

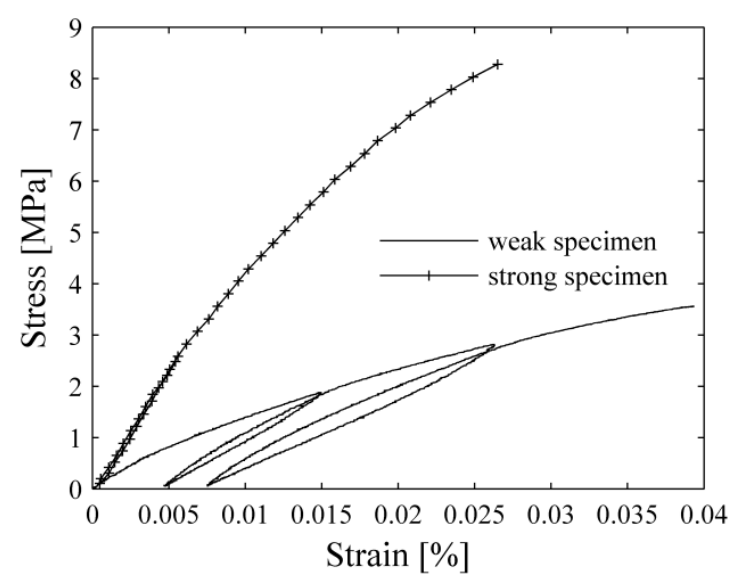

Fig. 5. Axial stress-stain behavior in tensile loading-unloading.

In addition to the quasi-static tensile tests, four high velocity direct tensile tests are performed using a hydraulic press with jack speed of $0.2 \mathrm{~m} / \mathrm{s}$. The results from high velocity direct tensile tests are summarized in Table 3. The very low tensile strength in specimen S12 corresponds to the presence of the previously discussed large initial cracks. The average tensile strength at the intermediate strain rates is slightly higher than the one from quasi-static tensile tests (excluding the strong specimens S99 and S100). This may be due to the strain rate dependence of such material. However, dynamic tests at higher strain rates (e.g. spalling tests) are to be performed in order to investigate this rate dependence in detail. 
Table 3 Mechanical properties of granite determined from high velocity direct tension test.

\begin{tabular}{|l|l|l|l|}
\hline Specimen & $\begin{array}{l}\text { Ultimate } \\
\text { Strength } \\
(\mathrm{MPa})\end{array}$ & $\begin{array}{l}\text { Strain rate } \\
\left(\mathrm{s}^{-1}\right)\end{array}$ & Instrument \\
\hline S6 & 6.2 & 0.051 & Gauge+Laser \\
\hline S11 & 5.9 & 0.044 & Gauge+Laser \\
\hline S12 & 2.4 & 0.025 & Gauge+Laser \\
\hline S18 & 5.7 & 0.047 & Gauge+Laser \\
\hline
\end{tabular}

\section{Quasi-oedometric compression tests}

Among the other techniques used to characterize the behavior of geomaterials under high-confining pressure, the so-called quasi-oedometric compression test is used in this work (see Fig. 6). During such a test, a cylindrical specimen tightly enclosed in a confinement cell is axially compressed [20], [21]. Four strain gauges are glued on the external surface of the confinement ring in the hoop direction. The radial stress and strain within the specimen can be obtained from gauge readings [21]. Further, the barreling of the ring is evaluated from the off center strain gauges (no plastic deformation is introduced in the ring).

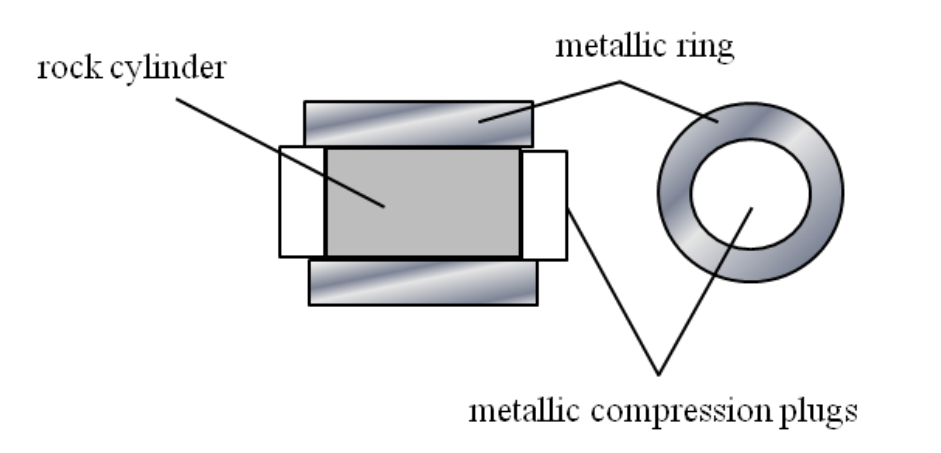

Fig. 6 Schematic of the quasi-oedometric compression test setup.

Both axial and radial stresses increase during loading as the material expands in the lateral direction. This gives an indication of the strength of the material at different levels of hydrostatic pressure. The deviatoric and volumetric response of the material can be obtained from this test.

Granite cylinders $28.9 \mathrm{~mm}$ in diameter and $40 \mathrm{~mm}$ in length (cut using diamond core drill machine) were loaded at a quasi-static strain rate of $10^{-3} \mathrm{~s}^{-1}$ and more than 700 samples were recorded for each test. Two tests were conducted and the results are very similar. The maximum load of the machine reached $1100 \mathrm{kN}$ during the test corresponding to a hydrostatic pressure of $864 \mathrm{MPa}$ in the rock specimen. The axial and radial stresses are shown in Fig. 7 as functions of the axial strain. 


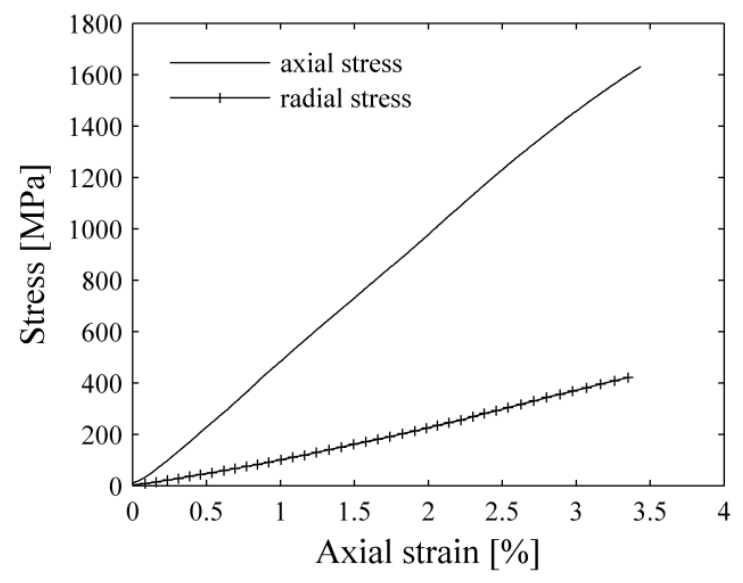

Fig. 7 Axial and radial stress in the specimen depicted as functions of axial strain.

The hydrostatic pressure versus volumetric strain is shown in Fig. 8 (a) and the deviatoric stress versus pressure is plotted in Fig. 8(b). The deviatoric response of the material is mostly linear with a small nonlinearity in the higher pressure part. The volumetric response, however, is virtually linear in the whole loading range with a constant bulk modulus. This linear response is due to the fact that the material just contains a very small amount of porosity $(0.2 \%)$ which is different from the case of porous rocks where the bulk modulus decreases noticeably due to porosity collapse [22]. When the pores are closed, the material exhibits a higher bulk modulus, which corresponds to the compacted material response.

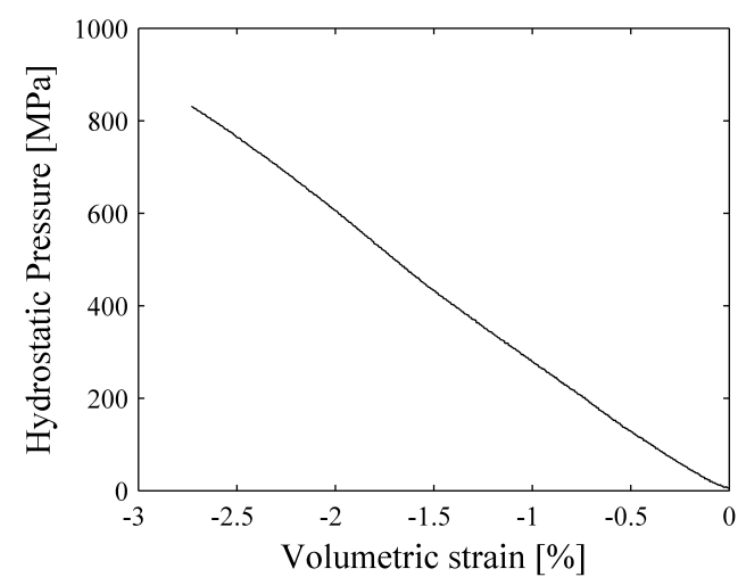

(a)

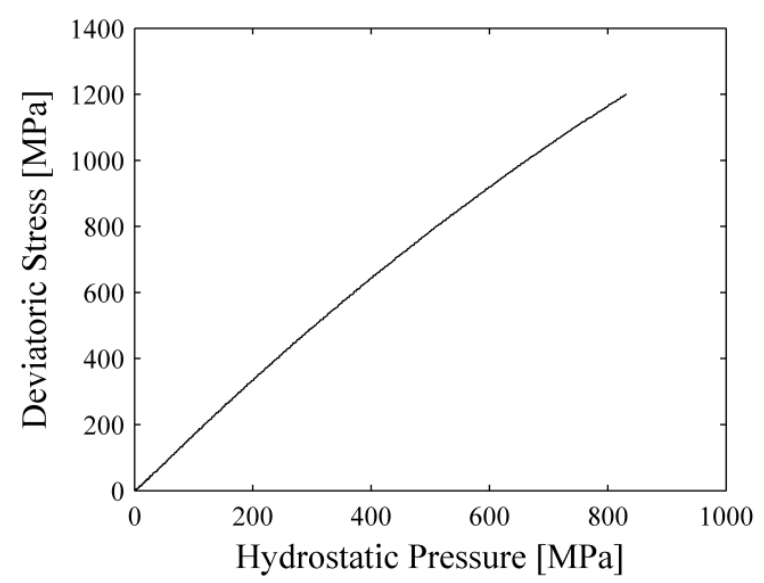

(b)

Fig. 8 Volumetric (a), and deviatoric response of granite (b) determined from quasi-oedometric compression test.

\section{Flexural tests}

Tensile failure of brittle materials depends upon the microstructure in terms of flaw density and failure stress distribution. To evaluate the quasi-static strength of the studied rock and its distribution, three-point bend (3PB) tests are carried out and Weibull statistics is used to describe the strength distribution [23], [24]. 


\subsection{Flexural test with strain gauges}

Parallelepiped specimens of size $20 \times 20 \times 100 \mathrm{~mm}^{3}$ and $40 \times 40 \times 150 \mathrm{~mm}^{3}$ are loaded quasi-statically with a strain rate of $10^{-4} \mathrm{~s}^{-1}$ up to the failure point and more than 200 samples were recorded for each test. The tensile surfaces of the specimens are carefully polished before the test to eliminate possible surface defects induced by their preparation. Strain gauges are placed on some of the specimens in the middle of the tensile surface.

The nominal stress is defined based on Bernoulli beam theory from the actuator force $P$, and the support distance $l$ as

$$
\sigma_{N}=\frac{6 P l}{4 b h^{2}}
$$

where $h$ is the height of the sample and $b$ the width. The nominal stress-strain curve in most of the specimens is mainly linear before the maximum load, followed by a brittle behavior leading to final failure. Accordingly, the Bernoulli beam theory may be employed to obtain the tensile strength of the material. The elastic modulus is about $52 \mathrm{GPa}$ in these specimens. The strain data from the two gauges with different length, 10 and $30 \mathrm{~mm}$, both glued on the middle of the tensile surface of a strong specimen, are very similar, see Fig. 9.

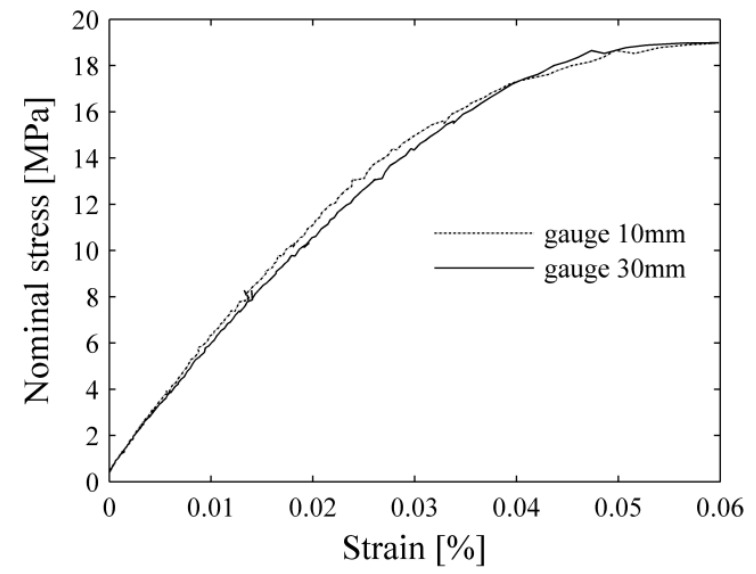

Fig. 9 Nominal stress-strain behavior in 3PB test of one strong specimen.

However, some specimens showed a significant non-linearity in the nominal stress-strain curve with a noticeably lower load capacity compared with the others. This behavior was as previously discussed also found in uniaxial tensile tests. The stress-strain data for one of these weak specimens is shown in Fig. 10 with strain data obtained from the 10 and $20 \mathrm{~mm}$ gauges. Firstly the degradation of the stiffness is clear from the results. Secondly the strain values from the two gauges are very similar initially, but they become different at increased load. This is an indication of crack openings during loading. The longer the strain gauge, the smaller the strain value if there are cracks in addition to the strain of the intact material. This will be discussed further in the next section. 


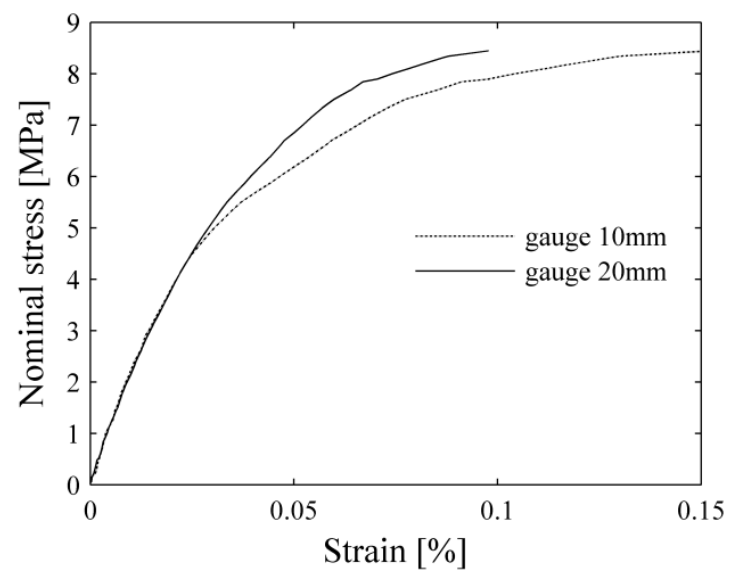

Fig. 10 Nominal stress-strain behavior in 3PB test of one weak specimen.

\subsection{Flexural test analyzed with digital images}

To further investigate the crack openings during loading, digital images are taken from the tensile surface of the specimens during the 3PB test. The surfaces of the specimens are coated with small dots randomly distributed by using paint spray. Digital Image Correlation (DIC) is then performed to measure the displacement field on the surface. The ARAMIS system with two cameras of 1.3-Mpixel definition is used in this investigation and the experimental setup is shown in Fig. 11.

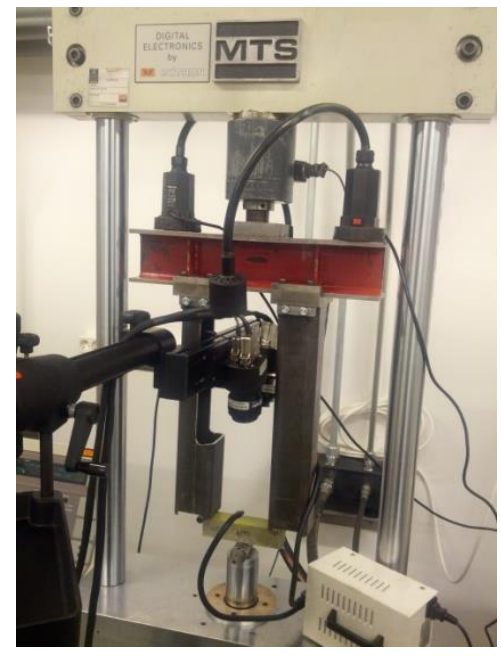

Fig. 11 Experimental setup for 3PB test with digital image acquisition.

Fig. 12 and Fig. 13 show the maximum principal strain field for two specimens during different loading stages. The specimen in Fig. 12 has a large initial defect that was visible before loading. As seen in the results (Fig. 12), the strain concentration region occurs on the surface and leads to the final failure. This region, which corresponds to crack opening, starts to form very early during loading (about $40 \%$ of the maximum load). 

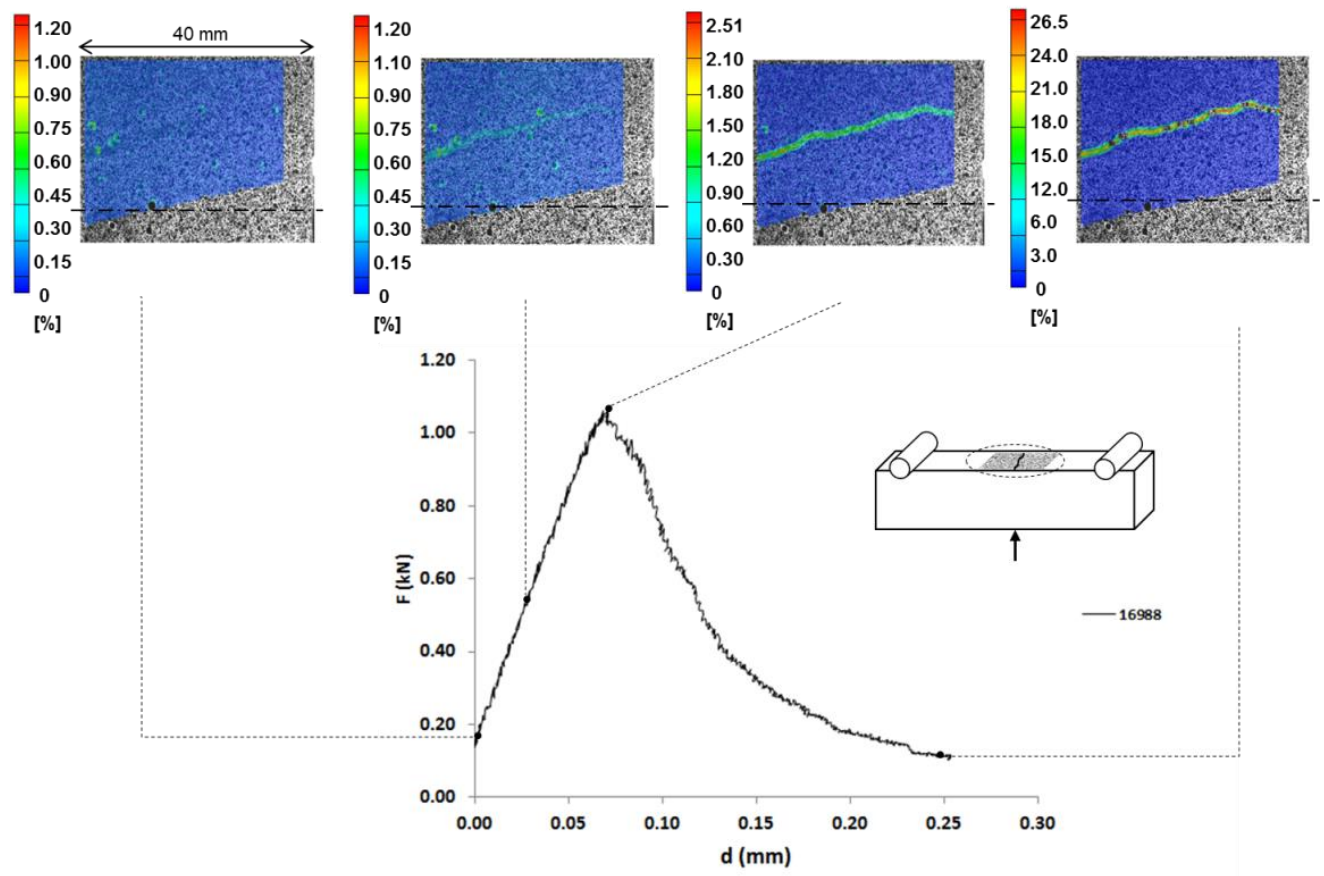

Fig. 12 Force-displacement of actuator and DIC results for 3PB test of a weak specimen.

In the strong specimen on the other hand, the strain concentration does not occur before $95 \%$ of the maximum load (see Fig. 13). It is followed by a brittle behavior leading to the final failure. The material response before the maximum load can be assumed to be linear. 


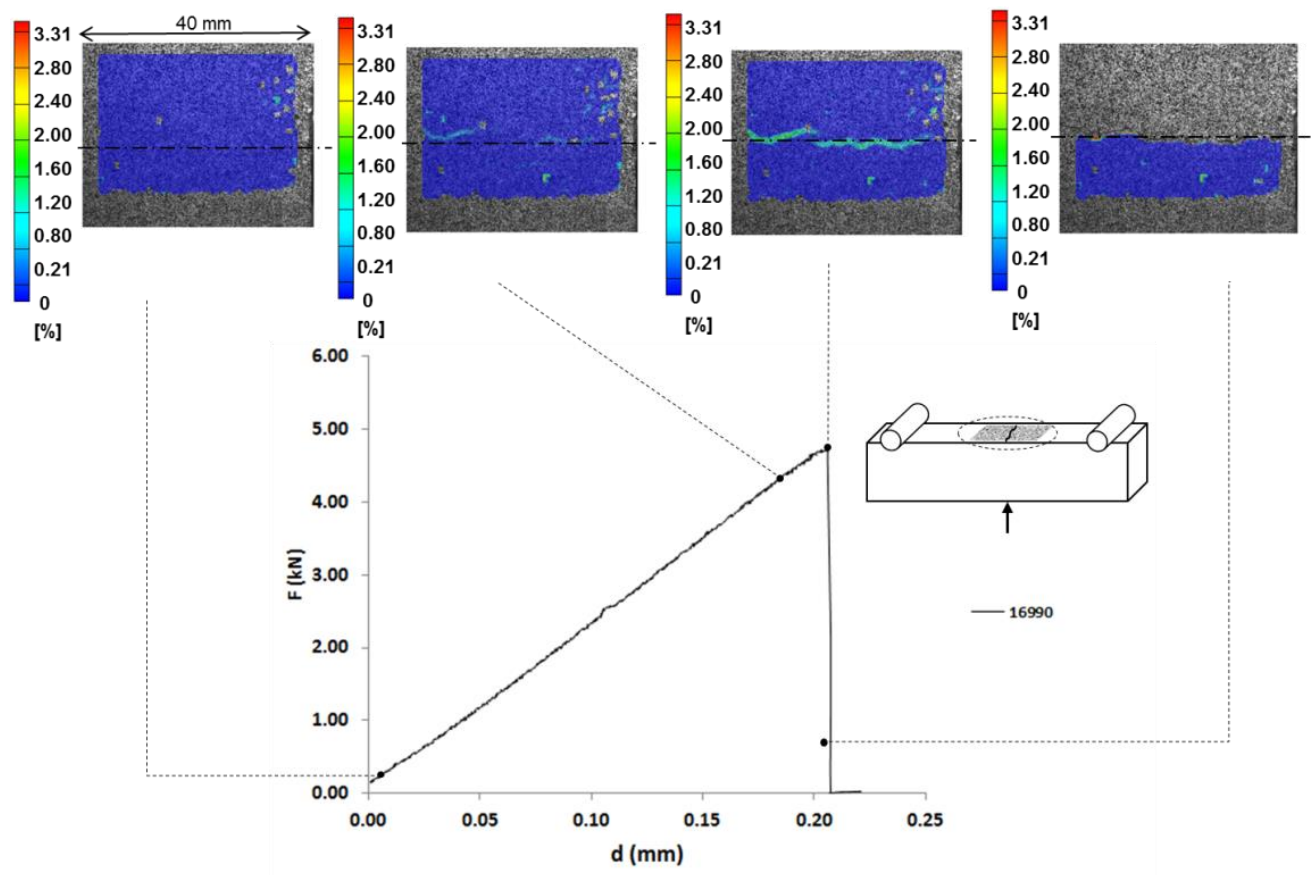

Fig. 13 Force-displacement of actuator and DIC results for 3PB test of a strong specimen.

\subsection{Weibull statistics}

Weibull statistics will now be employed to describe the strength distribution of the material. In order to obtain the Weibull parameters of the material, the weak specimens as described above are not considered initially. This is because of the fact that the initial defect in these specimens is so large that it can be treated more as a structural type defect rather than a material feature. It should be mentioned that these large defects were even visible initially on the surface of a few specimens. Alternative ways to include the structural cracks in the analysis (and also in the constitutive description) will be discussed below.

The results of the bending tests, for both the small and large specimens, are plotted in Fig. 14 in which the failure stress are sorted in ascending order and the failure probability $P_{F}$ of the $i$-th test is obtained from

$$
P_{F}=\frac{i-0.5}{n}
$$

where $n$ is the total number of tests for a given volume. The failure stress is calculated from the actuator force $P$, and the support distance $l$ using the Bernoulli beam theory (see Eq. (1)).

One classical way to obtain the Weibull modulus $m$ is then to look at the slope of the linear interpolation in the so-called Weibull plot, $\ln \left[-\ln \left(1-P_{F}\right)\right]$ versus $\ln \left(\sigma_{F}\right)$ where $\sigma_{F}$ is the stress to failure. The mean tensile strength and the Weibull modulus of the material obtained from the 3PB tests are summarized in Table 4. It should be noted once again that the results in Table 4 correspond to a case where only strong specimens (according to the force-displacement curves) are considered. The Weibull modulus obtained from the two specimen sizes are fairly close to each other. The Weibull size effect is written as 


$$
\frac{\sigma_{m 1}}{\sigma_{m 2}}=\left(\frac{V_{e f f 2}}{V_{e f f 1}}\right)^{1 / m}
$$

where $\sigma_{m l}$ and $\sigma_{m 2}$ are the mean failure strength of the specimens with different sizes, $V_{\text {effl }}$ and $V_{\text {eff } 1}$ are the effective volumes [25] being, for 3PB testing, functions of total volume $V$ and Weibull modulus [26] as

$$
V_{e f f}=\frac{V}{2(1+m)^{2}}
$$

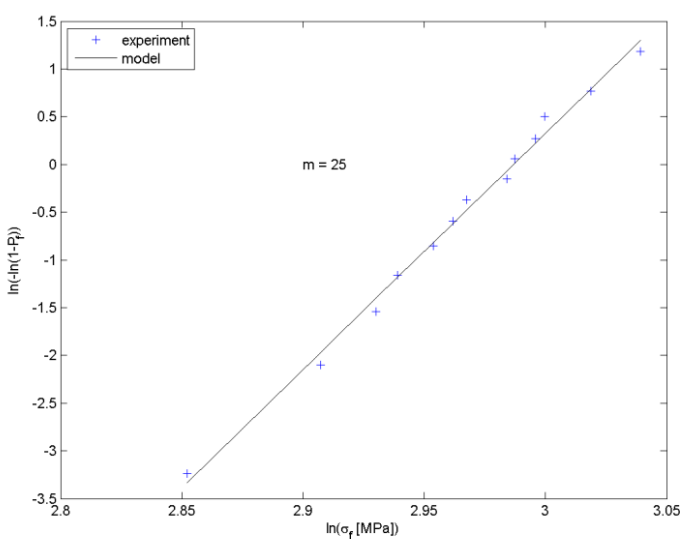

(a)

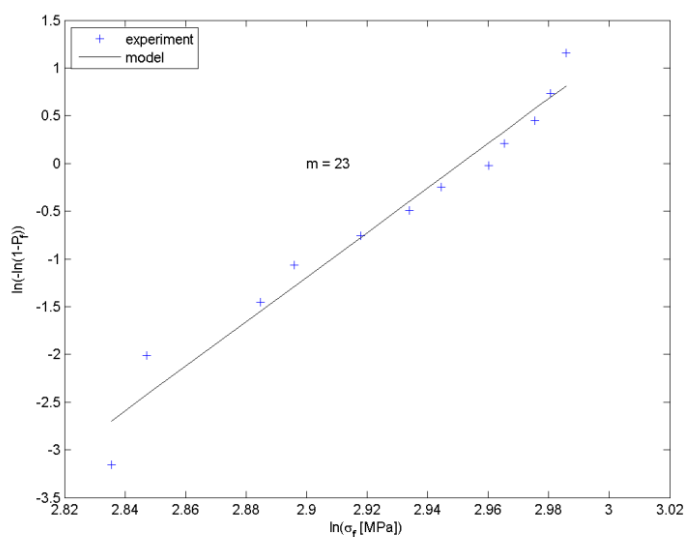

(b)

Fig. 14 Weibull plot to identify the Weibull modulus from 3PB tests on small (a), and large specimens (b).

Table 4 Experimental data determined from 3PB tests.

\begin{tabular}{|l|l|l|l|l|}
\hline Specimen & $\begin{array}{l}\text { Support } \\
\text { distance } \\
(\mathrm{mm})\end{array}$ & $\begin{array}{l}\text { Mean } \\
\text { tensile } \\
\text { strength } \\
(\mathrm{MPa})\end{array}$ & $\begin{array}{l}\text { Weibull } \\
\text { modulus } \\
m\end{array}$ & $\begin{array}{l}\mathrm{V}_{\text {eff. }} \\
\left(\mathrm{mm}^{3}\right)\end{array}$ \\
\hline $20 \times 20 \times 100\left(\mathrm{~mm}^{3}\right)$ & 76.5 & 19.2 & 25 & 23 \\
\hline $40 \times 40 \times 150\left(\mathrm{~mm}^{3}\right)$ & 140.0 & 18.7 & 23 & 189 \\
\hline
\end{tabular}

To evaluate a unique set of Weibull parameters, namely analyzing both the small and large specimens in one set, the so-called Weibull stress $\sigma_{w}$ [27] is computed,

$$
\sigma_{w}=\sigma_{F}\left(\frac{V_{e f f}}{V_{0}}\right)^{1 / m}
$$

where $\mathrm{V}_{0}$ is an arbitrary reference volume. For a given initial value of the Weibull modulus (say one of those identified previously) the Weibull stress of any test on small and large samples is computed. The set of Weibull stresses is sorted in ascending order and all the data are plotted in a modified Weibull plot, $\ln \left[-\ln \left(1-P_{F}\right)\right]$ versus $\ln \left(\sigma_{w}\right)$. The slope gives a new estimate of the Weibull modulus. By iterating this 
process a few times a unique and converged value of Weibull modulus $m=23$ is obtained. Fig. 15 shows that the two test series are distributed over a large part of the probability axis, thereby indicating that a single set of Weibull parameters can be deduced from this combined analysis.

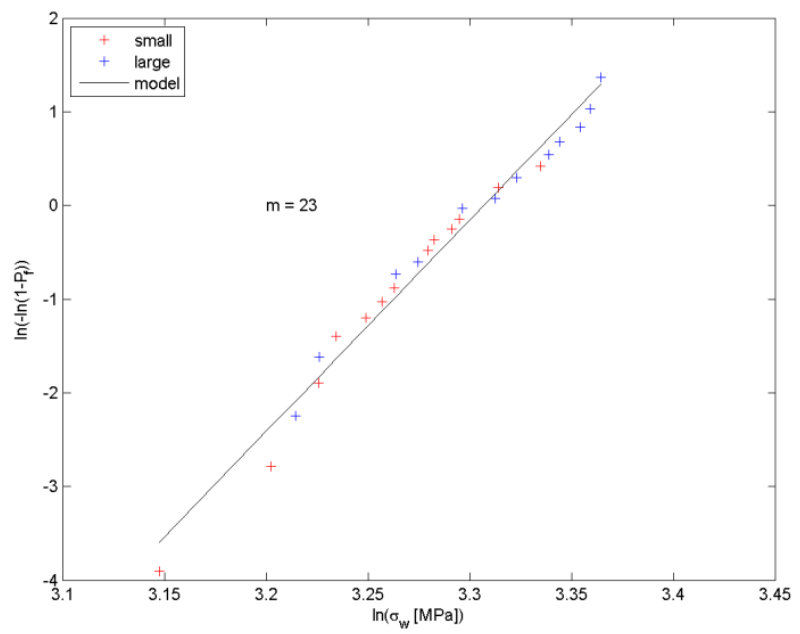

Fig. 15 Modified Weibull plot to identify a single Weibull modulus from 3PB tests on small and large specimens.

In a mechanical analysis of a problem related to granite rock materials, for example in a drilling situation, the damage characteristics is then appropriately described by the results in Fig. 15 with the explicit value on the Weibull modulus $m$ being 23. In such an approach, the structural cracks discussed above are not considered (this is presently referred to as an intact material) but could be accounted for by introducing a finite number of initial cracks in the analyzed structure. The validity of such a constitutive description where only micro-cracks are accounted for is further supported by the fact that present observations indicate that structural cracks are mainly formed due to the sample preparation, for example cutting. Accordingly, when virgin granite material is at issue, for example in an initial drilling situation, such cracks will be few or practically nonexistent.

It is of course possible to also suggest that the structural cracks can be treated as material characteristics indicating that two defect populations must be considered in the constitutive description. In such an approach, the results from both the weak and strong specimens must be included in the Weibull plot and a bimodal Weibull distribution is then used to account for the two defect populations [28], see Fig. 16. This results in the $m$-values $m_{1}=2.5$ and $m_{2}=29$. The lower Weibull modulus in this curve corresponds to the structural cracks with large scatter in size and location. It should be immediately emphasized though that in such an approach the maximum stress in the specimen is not correctly determined from Eq. (1) and accordingly the strength of the (weak) specimens is unknown. Furthermore, the scatter in size and location of these structural cracks will be different for each set of specimens and as a consequence, adding additional experimental results relevant to weak specimens can substantially change the value on $m_{1}$. 


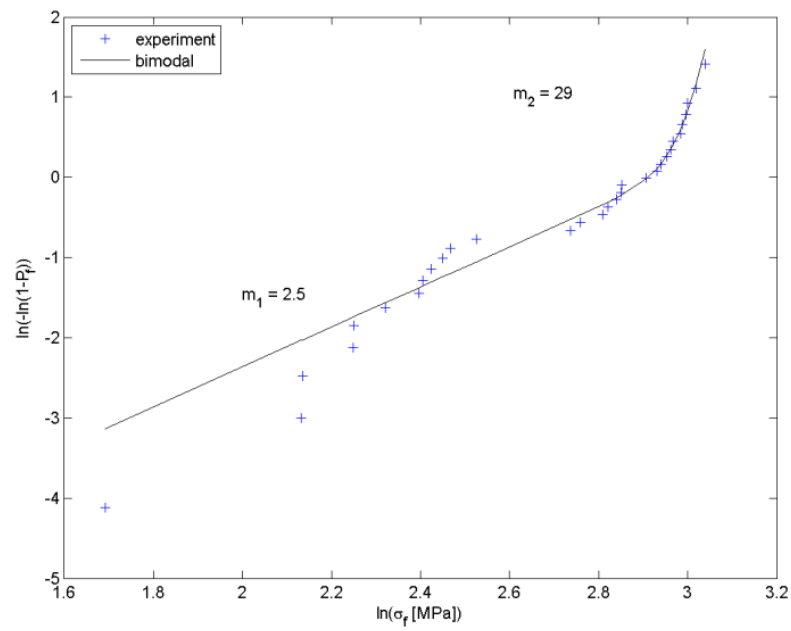

Fig. 16 Bimodal Weibull plot including all the weak and strong small specimens in 3PB test.

\section{Pre-existing cracks in granite}

Having so discussed above the execution and outcome of the experimental tests it seems natural to also discuss some further the specific issue of pre-existing cracks. Such cracks are not an immediate factor when building constitutive equations but are nevertheless a very important feature in a mechanical analysis of granite. It should be noted that it has also previously been reported [7] that granite rock contains many pre-existing cracks.

The size of the pre-existing cracks is, as determined in the present study, very approximately up to a few millimeters. A mesoscopic image from the surface of granite is shown in Fig. 17. The dark regions in the picture correspond to cracks and faults. As can be seen, a couple of open cracks are visible. However, any obvious anisotropy in the orientation of these cracks is not observed on the macroscopic scale. 


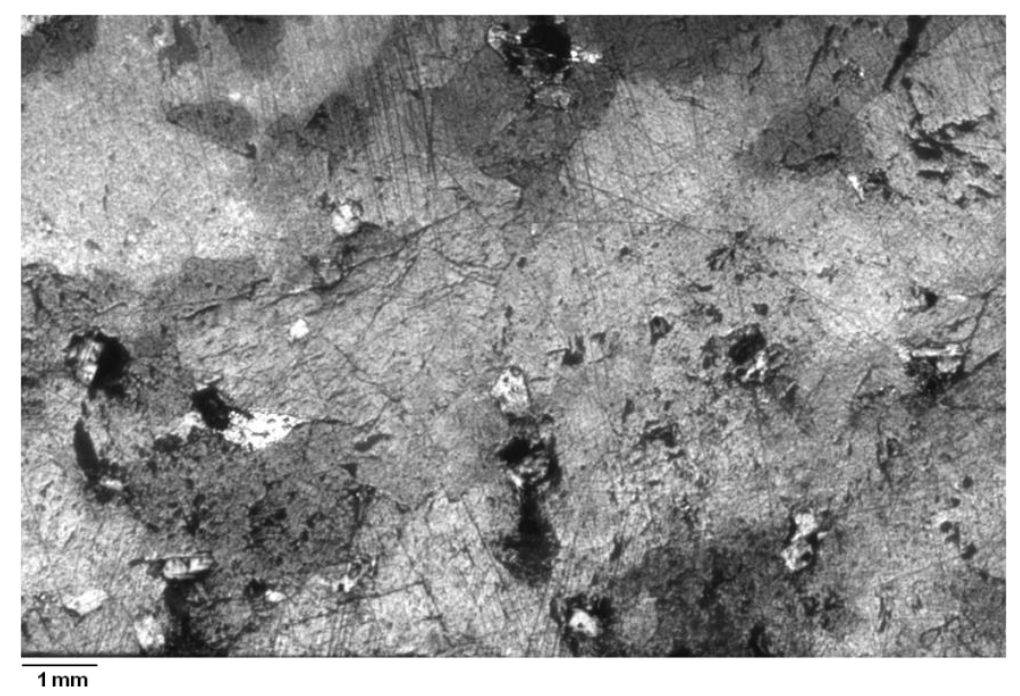

Fig. 17 Mesoscopic image from the surface of a specimen, $\mathrm{mm}$ scale is shown in the image.

The problem of stiffness reduction of a cracked body has been widely investigated [29], [30]. Kachanov [31] proposed a simple method to evaluate the effective stiffness of a linear elastic material with $N$ noninteracting micro-cracks. The effective compliance of the material including penny shaped cracks with the density $\rho$ (i.e., number of cracks per unit volume) and length $a$ is expressed as

$$
\boldsymbol{S}_{e f f}=\boldsymbol{S}_{m}+\rho a^{3} \frac{16\left(1-v_{m}^{2}\right)}{3 E_{m}\left(2-v_{m}\right)}\left(2 \boldsymbol{N}^{T} \boldsymbol{N}-v_{M} \boldsymbol{N}^{T} \boldsymbol{n} \boldsymbol{n}^{T} \boldsymbol{N}\right)
$$

where $\boldsymbol{S}_{\text {eff }}$ is the effective compliance tensor, $\boldsymbol{S}_{m}$ and $v_{m}$ the intact material compliance tensor and Poisson's ratio, $\boldsymbol{n}$ the normal vector to the crack face with components $n_{x}, n_{y}, n_{z}$, and $\boldsymbol{N}$ is defined by

$$
\boldsymbol{N}=\left[\begin{array}{cccccc}
n_{x} & 0 & 0 & n_{y} & n_{z} & 0 \\
0 & n_{y} & 0 & n_{x} & 0 & n_{z} \\
0 & 0 & n_{z} & 0 & n_{x} & n_{y}
\end{array}\right]
$$

To simplify the problem, only the cracks normal to the loading direction are considered. The only nonzero component of the normal vector would then be $n_{x}, n_{y}$ or $n_{z}$ and Eq. (6) is simplified as

$$
\frac{1}{E_{e f f}}=S_{e f f}=S_{m}+\rho a^{3} \frac{16\left(1-v_{m}^{2}\right)}{3 E_{m}}
$$

The effective stiffness of a $1 \mathrm{~mm}^{3}$ cube is plotted as function of the crack density and crack length (Fig. 18). The effective stiffness degrades about $15 \%$ if the cube has two horizontal cracks of $0.5 \mathrm{~mm}$ size. 


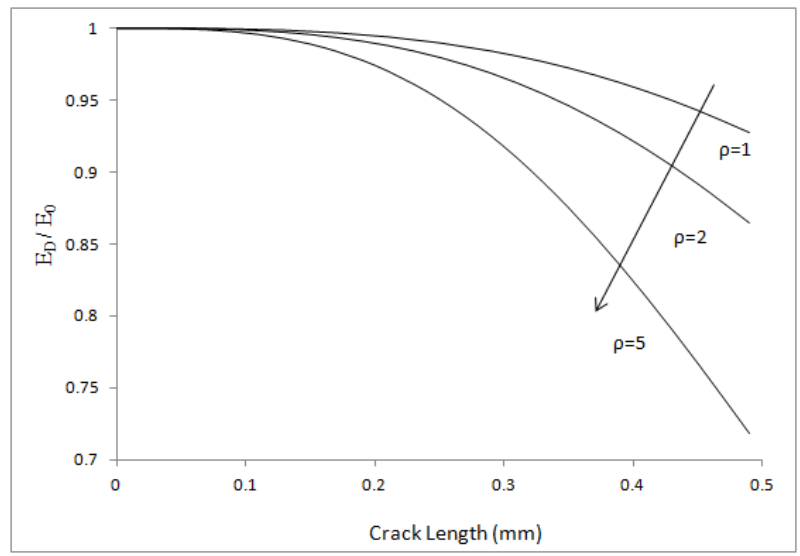

Fig. 18 Elastic modulus reduction of a cracked body $\left(1 \mathrm{~mm}^{3}\right.$ cube) as determined from Eq. (8).

\section{Conclusions}

The present experimental investigation aims at material characterization of Bohus granite pertinent to advanced constitutive models including the issue of dynamic fragmentation. The KST-DFH model naturally then comes to mind but considering the general experimental approach taken, it should be possible based on the results to also determine the material parameters in other constitutive models for rock materials with the intention to perform finite element analyses of the mechanical behavior of granite.

A very important feature of the granite material is the large number of initial cracks, both at the grain boundaries and also across the grains. In addition to that, some samples had structural bulk or surface cracks, here called weak specimens, which cause significant stiffness and load capacity reduction. Direct tensile and compression tests are performed and the mechanical properties of the material such as stiffness and strength are obtained. A significant non-linear stress-strain behavior in both compression and tension is captured from the weak specimens. A damage mechanism prevails in the tensile case with the degradation of the stiffness due to open cracks. In the compression tests, the elastic modulus gradually increases in the beginning and then becomes equal to $52 \mathrm{GPa}$ when increasing the load level. This suggests that all of these weak specimens had initially one or many large structural defects in the bulk that cause a stiffness reduction of about $40 \%$. On the other hand, the strong specimens show a linear-like behavior during both tensile and compression tests. In tension, the stress-strain curve is mainly linear before the maximum load followed by a rapid brittle failure. In compression tests, the stiffness increases slightly due to the closure of the pre-existing material cracks.

Quasi-oedometric tests are carried out in order to obtain the deviatoric and volumetric response of the material at different levels of hydrostatic pressure. The deviatoric response of the material is mostly linear with a very small non-linearity in the higher pressure part. The volumetric response, however, is almost linear in the whole loading range. This result is due to the very small amount of porosity $(0.2 \%)$ in the material.

3PB tests are performed to evaluate the quasi-static strength of the rock and also its statistical distribution. Strain gauges are used in some of the tests to further investigate the strain data. Some specimens also had two strain gauges with different lengths. In most of the specimens, the stress-strain curve is mainly linear 
before the maximum load, followed by a brittle behavior leading to the final failure. There are some specimens that show a significant non-linearity in the force-strain curve with a noticeably lower load capacity. The large difference between the strain values from the two gauges in these specimens suggests that the crack is open on the tensile surface at an early stage. These specimens have, as was the case also in uniaxial tension and compression tests, initial bulk structural defects. Digital Image Correlation (DIC) is performed on a few tests and it is demonstrated that in the specimens with initial structural defects, the crack is open early during loading. It is also shown that the crack gradually propagates followed by a semi-brittle behavior that leads to total failure. Weibull statistics is used to describe the strength distribution. The so-called Weibull stress is used to obtain the Weibull modulus for all the specimens with different sizes as one unique set.

The structural cracks in granite specimens must be carefully accounted for as they have a significant influence on the mechanical behavior of the material. As some of these cracks are in the bulk of the specimens, one may think of a number of simple ways to determine their presence. In 3PB tests, using two strain gauges with different lengths is a simple alternative. Any difference in the stress-strain data from the two gauges at an early loading stage and also a large difference in the strain value at the failure point may be interpreted as the presence of structural crack. When the strain gauge is longer, the strain value decreases if there is a gap in the material due to the open cracks, in addition to the strain of the matrix. Also digital images can be taken from the tensile surface of the specimens during the 3PB test and DIC can be performed to investigate if the cracks are open early during loading. If so, it means that the specimen includes structural cracks. Loading-unloading in direct tensile test can be performed and a large inelastic strain at the end of each unloading stage is a sign of open cracks that are not closed completely and leave irreversible strains. A significant stiffness increase during a direct compression test may be interpreted as closure of structural cracks in the specimen. Finally, the scatter in the tensile strength of the intact granite material is not high in the 3 PB test with a Weibull modulus of about 23. Therefore, any high scatter in the result due to a few weaker specimens must be carefully investigated.

In the present context, it seems appropriate, for clarifying reasons, to summarize the experimental results achieved in the present investigation. First of all then, the results pertinent to uniaxial compression and tension testing is shown in Tables 1,2 and 3. These results concern elastic modulus and strength values and relates to specimens with and without pre-existing cracks. The discussion in relation to these tables makes it possible to distinguish the results for each feature. Furthermore, the plastic behavior of the material is determined from quasi-oedometric tests as visualized in Fig. 8 and finally, the probabilistic damage behavior is studied in section 4 , by using flexural testing, and summarized in Table 4.

To conclude, based on the experimental results, a damage mechanism with stiffness reduction due to open cracks determines the rock mechanical behavior in tension. Dynamic effects with strain rate dependency play an important role that has to be considered [19]. In compression, rock has a plasticity-like behavior (corresponding to pore collapse, compaction and grain sliding and breakage) that depends on the level of hydrostatic pressure. The combination of these two sets of data gives a complete mechanical characterization of rocks subjected to different loading situations, including percussive drilling which is the main application of this work. The KST-DFH model combining a damage law in tension [2], [16] and plasticity, due to pore collapse, compaction and grain sliding and breakage, in confined compression [14], [15] is, as discussed repeatedly above, a likely candidate for this purpose and this will be further investigated using numerical (finite element) methods. It should be emphasized that in a mechanical 
analysis of a problem related to granite, for example in a drilling situation, the structural cracks discussed above could be accounted for by introducing a finite number of initial macrocracks in the analyzed structure. 


\section{References}

[1] Saksala, T., "Numerical Modelling of Rock Fracture in Percussive Drilling," PhD Thesis, Tampere University of Technology, Finland, 2010.

[2] Forquin, P., and Hild, F., "A Probabilistic Damage Model of the Dynamic Fragmentation Process in Brittle Materials," Adv. Appl. Mech., vol. Volume 44, 2010, pp. 1-72.

[3] Tan, X. C., Kou, S. Q., and Lindqvist, P.-A., "Application of the DDM and fracture mechanics model on the simulation of rock breakage by mechanical tools," Eng. Geol., vol. 49, no. 3-4, 1998, pp. 277-284.

[4] Fang, Z., and Harrison, J. P., "Development of a local degradation approach to the modelling of brittle fracture in heterogeneous rocks," Int. J. Rock Mech. Min. Sci., vol. 39, no. 4, 2002, pp. 443457.

[5] David, E. C., Brantut, N., Schubnel, A. Schubnel, and R. W. Zimmerman, "Sliding crack model for nonlinearity and hysteresis in the uniaxial stress-strain curve of rock," Int. J. Rock Mech. Min. Sci., vol. 52, 2012, pp. 9-17.

[6] Peng, S., and Johnson, A. M., "Crack growth and faulting in cylindrical specimens of Chelmsford granite," in International Journal of Rock Mechanics and Mining Sciences \& Geomechanics Abstracts, vol. 9, no. 1, ,1972, pp. 37-86.

[7] Bäckström, A., Antikainen, J., Backers, T., Feng, X., Jing, L., Kobayashi, A., Koyama, T., Pan, P., Rinne, M., Shen, B., and Hudson, J. A., "Numerical modelling of uniaxial compressive failure of granite with and without saline porewater," Int. J. Rock Mech. Min. Sci., vol. 45, no. 7, 2008, pp. $1126-1142$.

[8] Brady, B. H. G., Rock mechanics: for underground mining. Springer, 2004.

[9] Shimada, M., Cho, A., and Yukutake, H., "Fracture strength of dry silicate rocks at high confining pressures and activity of acoustic emission," Tectonophysics, vol. 96, no. 1-2, 1983, pp. 159-172.

[10] Liu, H. Y., Kou, S. Q., Lindqvist, P.-A., and Tang, C. A., "Numerical simulation of the rock fragmentation process induced by indenters," Int. J. Rock Mech. Min. Sci., vol. 39, no. 4, 2002, pp. 491-505.

[11] Wang, S. Y., Sloan, S. W., Liu, H. Y., and Tang, C. A., "Numerical simulation of the rock fragmentation process induced by two drill bits subjected to static and dynamic (impact) loading," Rock Mech. Rock Eng., vol. 44, no. 3, 2011, pp. 317-332.

[12] Saksala, T., "Damage-viscoplastic consistency model with a parabolic cap for rocks with brittle and ductile behavior under low-velocity impact loading," Int. J. Numer. Anal. Methods Geomech., vol. 34 , no. 13,2010 , pp. 1362-1386.

[13] Saksala, T., "3D numerical modelling of bit-rock fracture mechanisms in percussive drilling with a multiple-button bit," Int. J. Numer. Anal. Methods Geomech., vol. 37, no. 3, 2013, pp. 309-324.

[14] Krieg, R. D., “A simple constitutive description for soils and crushable foams," Report, SC-DR7260883, Sandia Natl. Lab., 1978.

[15] Swenson, D. V, and Taylor, L. M., "A finite element model for the analysis of tailored pulse stimulation of boreholes," Int. J. Numer. Anal. Methods Geomech., vol. 7, no. 4, 1983, pp. 469484.

[16] Denoual, C., and Hild, F., "A damage model for the dynamic fragmentation of brittle solids," Comput. Methods Appl. Mech. Eng., vol. 183, no. 3, 2000, pp. 247-258.

[17] Grange, S., Forquin, P., Mencacci, S., and Hild, F., "On the dynamic fragmentation of two 
limestones using edge-on impact tests," Int. J. Impact Eng., vol. 35, no. 9, 2008, pp. 977-991.

[18] Erzar, B., and Forquin, P., "Analysis and modelling of the cohesion strength of concrete at high strain-rates," Int. J. Solids Struct., vol. 51, no. 14, 2014, pp. 2559-2574.

[19] Forquin, P., and Erzar, B., "Dynamic fragmentation process in concrete under impact and spalling tests," Int. J. Fract., vol. 163, no. 1-2, 2010, pp. 193-215.

[20] Forquin, P., Gary, G., and Gatuingt, F., "A testing technique for concrete under confinement at high rates of strain," Int. J. Impact Eng., vol. 35, no. 6, 2008, pp. 425-446.

[21] Forquin, P., Safa, K., and Gary, G., "Influence of free water on the quasi-static and dynamic strength of concrete in confined compression tests," Cem. Concr. Res., vol. 40, no. 2, 2010, pp. 321-333.

[22] Vajdova, V., Baud, P., and Wong, "Compaction, dilatancy, and failure in porous carbonate rocks," J. Geophys. Res. Solid Earth, vol. 109, no. B5, 2004.

[23] Weibull, W., "A Statistical Theory of the Strength of Materials," Report 151, Royal Institute of Technology, Stockholm, 1939.

[24] Weibull, W., “A statistical distribution function of wide applicability,” J. Appl. Mech., vol. 18, no. 3, 1951, pp. 293-297.

[25] Davies, D. G. S., "The statistical approach to engineering design in ceramics," in Proc. Brit. Ceram. Soc, vol. 22, no. 6, 1973, pp. 429-452.

[26] Quinn, G. D., "Weibull strength scaling for standardized rectangular flexure specimens," J. Am. Ceram. Soc., vol. 86, no. 3, 2003, pp. 508-510.

[27] da Silva, A. R. C., Proença, S. P. B., Billardon, R., and Hild, F., "Probabilistic approach to predict cracking in lightly reinforced microconcrete panels," J. Eng. Mech., vol. 130, no. 8, 2004, pp. 931941.

[28] Gy, R., and Guillemet, C.,, "Characterization of a mode of rupture of glass at 610 C," Phys. NonCrystalline Solids, 1992.

[29] Budiansky, B., and O'connell, R. J., "Elastic moduli of a cracked solid,” Int. J. Solids Struct., vol. 12, no. 2, 1976, pp. 81-97.

[30] Horii, H., and Nemat-Nasser, S., "Overall moduli of solids with microcracks: load-induced anisotropy," J. Mech. Phys. Solids, vol. 31, no. 2, 1983, pp. 155-171.

[31] Kachanov, M., "Elastic solids with many cracks: a simple method of analysis," Int. J. Solids Struct., vol. 23, no. 1, 1987, pp. 23-43. 